
8 Research Square
Preprints are preliminary reports that have not undergone peer review.
They should not be considered conclusive, used to inform clinical practice,
or referenced by the media as validated information.

\title{
Trauma Experiences of African Men from a Refugee Background in Western Australia: A Cross-Sectional Study
}

Emest Obiechina Nnadigwe ( $\nabla$ ernest.nnadigwe@research.uwa.edu.au )

University of Western Australia https://orcid.org/0000-0002-7334-7027

Colleen Fisher

The University of Western Australia

Lisa Wood

The University of Western Australia

Karen Martin.

The University of Western Australia

\section{Research}

Keywords: Africa, Men, Trauma, Refugees, Western Australia

Posted Date: April 28th, 2021

DOI: https://doi.org/10.21203/rs.3.rs-407796/v1

License: () (1) This work is licensed under a Creative Commons Attribution 4.0 International License. Read Full License 


\section{Abstract \\ Background}

As people from the African continent continue to settle in Australia, exposure of men from African refugee backgrounds to potentially traumatic events not only impact negatively on their settlement but have also been linked to increased mental health issues and family and domestic violence. This study aims to describe the prevalence and dominant forms of potentially traumatic experiences of African men from a refuge background in Western Australia.

\section{Methods}

Survey data from 421 African men from Eritrea, Ethiopia, Rwanda, Republic of Congo-Brazzaville, Sierra Leone, Democratic Republic of Congo, Liberia, Sudan and South Sudan, Burundi and Somalia were analysed using descriptive statistics.

\section{Results}

The study showed that $81 \%$ of the participants experienced at least one potentially traumatic event either in their home country or in a refugee country. However, the prevalence of potentially traumatic events in their home country ranged from $45 \%$ (Somalia) to $95 \%$ (Democratic Republic of Congo) while in refuge countries, the potentially traumatic experience prevalence ranged from 17\% (Somalia) to 51\% (Sudan and South Sudan). The majority of the participants (64\%) experienced "War at close quarter" in their home country. In comparison, the dominant potentially traumatic experience in refuge countries was "Forced Separation" (28\%). The study showed that $53 \%$ of the participants who experienced one or more potentially traumatic events in their home country also experienced one or more potentially traumatic events in the refugee country.

\section{Conclusions}

This study will provide baseline data on the prevalence and dominant forms of potentially traumatic events of African refugee men now resident in WA. The impact of potentially traumatic events should be addressed in counselling, and other interventions developed and delivered by both government and nongovernment agencies.

\section{Background}

Ethnic conflicts, political violence, and wars in many parts of Africa have been associated with migration and forced displacement of community members due to their overwhelming trauma and lack of safety [1]. With such instability, conflict and war impact the health and wellbeing of populations significantly, with many acts potentially causing trauma for those who experience or witness such events [2]. Potentially traumatic events are events such as wars and personal experiences that cause extreme stress to an individual as described in the Diagnostic and Statistical Manual of the American Psychiatric Association, fifth edition [3]. In the 1980s, twenty percent of the refugees who experienced potential traumatic events migrated to Australia, Canada, and the United States (US) [4]. Migration of African refugees to other parts of the world including the USA and Australia increased between 1960 and 2000 [5].

The steady increase in Australian migration necessitated the Australian Federal Department of Immigration to be established in 1945 after more than 170,000 migrants, mainly from Eastern Europe, arrived in the late 1940s [6]. Flows of migrants and refugees continued with the first African refugees from Somalia arriving in Australia in the 1980s [7]. Since then, there has been a substantial increase in the number of African refugees from war-torn African countries including Burundi, Congo Brazzaville, Democratic Republic of Congo (DRC), Rwanda, Guinea, Liberia, Sierra Leone, Ethiopia, Eritrea, and Sudan [8]. Their settlement in Australia often followed experiences of trauma and suffering in their country of birth $[7,9]$ and their lives are invariably impacted by their premigration experiences, including experiences of potentially traumatic events [10].

The specific impact of war-related trauma is a significant factor associated with mental health issues [11]. This has been demonstrated in studies from several different countries that have experienced war, and in youth and adult refugee populations [12-14]. For example, a study conducted in Lebanon by interviewing participants from four Lebanese communities exposed to war in their countries, showed that the prevalence of psychiatric disorders during the years of war was strongly related to exposure to war-related potentially traumatic events $[15,16]$. Studies with refugee youths indicate that exposure to warrelated trauma has negative consequences, including adjustment difficulties, behavioural problems and other psychiatric issues [17].

The mental health conditions of refugees exposed to war in African countries has been associated with the potentially traumatic events they experienced in the wars. Liberian and Sierra Leonean refugee men living in refugee camps in Guinea have reported feelings of vulnerability and powerlessness, which are commonly observed psychological consequences of war torture [18]. Refugees in Kenya from Sudan, Somalia, Congo (DRC), Ethiopia, Rwanda, and Burundi who have been victims of torture are highly traumatised and continued to suffer psychological effects from their experiences [19]. Furthermore, former soldiers of Congo (DRC) in Germany, who indicated they had perpetrated a violent act had more severe rating (mean $=24.22)$ of Post-Traumatic Stress Disorder (PTSD) symptoms compared with those who reported having experienced non-war-related potential traumatic events $(M=16.19)[20]$.

Substantial evidence documents the impacts of prolonged mental health on trauma victims as their health conditions hinder their capacity to function independently in their communities, and hence additional supports are often provided to refugees [21-24]. Through Humanitarian Settlement Services (HSS), the Australian government, for example, offers counselling support and information to meet the initial service needs of refugees for up to one year from the date of arrival in the country [25]. The short-term torture and trauma counselling for new arrivals under the HSS programme, however, is not sufficiently robust 
in terms of the number of counselling sessions and focus that will restore trust to the trauma victims and help them live a normal life free of fear and anxiety [26]. Understanding the prevalence and pervasive impact of war-related potential traumatic events, therefore, is crucial to enable the formulation and implementation of appropriate trauma-informed interventions and treatments for those exposed [27]. This evidence is currently lacking.

There have been studies on experiences of Africans from refugee backgrounds in Western Australia (WA) such as the impact of their visa status and Medicare eligibility [28], the sexual health of Africans in WA and their settlement [26, 28]; and family and domestic violence [10] after they migrated to Australia. However, there appears to be no research about the exposure of African men to potential traumatic events before they migrated to Australia. Such research has the potential to inform the development of appropriate interventions for African men who have experienced war trauma. The current study fills this gap in knowledge by examining the trauma experiences of African men from a refugee background in WA.

\section{Methods}

The approval for this study was obtained from Human Ethics of The University of WA (reference - RA/4/20/5653).

\section{Aim}

The overall aim of this study was to investigate the prevalence and dominant forms of traumatic experiences of refugee men in WA, from the top ten WA migrant African countries of birth whose wars ended between 1990 and 2009 [29-37]. The secondary aim of the research was to identify differences in traumatic experiences for men from the different countries.

\section{Study design}

This study is a component of a broader mixed-methods study examining the association between a culture of masculinity, traumatic experiences, and attitudes towards family and domestic violence. Reported in this paper are the results of the first phase of the study, which examines the potentially traumatic events experienced by African refugee men before their settlement in Australia. For the purpose of this study, the United Nation's definition of refugee [4] was used and a "traumatic event" was defined as an occurrence in which a person felt, witnessed or faced actual or threatened death or serious injury or a threat to the physical integrity of one's self or others [38]. A traumatic event is not limited solely to the traumatic situation, but it involves socio-psychological processes [39].

This study phase incorporated a cross-sectional quantitative design [40]. A validated survey instrument, the Refugee Trauma History Checklist (RTHC) questionnaire [41] was incorporated and modified for this study. The modified RTHC is appropriate in this study as it provides self-report data on refugee trauma history [45] and consists of two sets of eight items concerning potentially traumatic events that occurred in the Country of Birth and/or the Refugee Country, such as: 1) War at close quarters, 2) Forced separation from family or close friends, 3) Loss or disappearance of loved one(s), 4) Physical violence or assault, 5) Witnessing physical violence or assault, 6) Torture, 7) Sexual violence, and 8) Other frightening situation(s) where the participant felt his life was in danger. The questionnaire was available in English, French and Swahili, which are the languages commonly spoken by potential participants [44].

\section{Study population}

This study was carried out in Perth, WA, a city with a population of over two million [42]. In 2017, there were approximately 6,538 African refugees in Western Australia, of which approximately 3,324 were African men from the countries of interest [43], the majority of whom lived in Perth. Non-probability sampling [44] was used in recruiting the study participants. Inclusion criteria for the study comprised being male, aged between 18 years and 70 years, residing in WA and being of African descent from either Eritrea, Ethiopia, Rwanda, Republic of Congo-Brazzaville, Sierra Leone, Congo (DRC), Liberia, Sudan/South Sudan, Burundi or Somalia.

\section{Recruitment and data collection}

The second author contacted the Office of Multicultural Interests (OMI)[1]. The first author also contacted eleven African organisations in WA for the purpose of raising awareness of the study and seeking support for the distribution of the questionnaires to participants. Copies of the questionnaire were administered between December 2019 to March 2020 in both hardcopy and on-line format (generated using Qualtrics). Information about the research and a link to the online questionnaire was included in the OMI weekly newsletter for 20 weeks and appeared on the websites and Facebook pages of those African organisations who agreed to support study recruitment. The first author distributed hardcopy questionnaires at community events of the respective African communities such as community meetings and sporting, at which the prospective participants completed the questionnaire.

\section{Sample size}

An estimate of $37 \%$ prevalence of trauma among African refugees was used in the power analysis to calculate the sample size needed to estimate the prevalence of potentially traumatic events of men of African descent in WA. [45]. This estimate was determined from previous trauma, posttraumatic disorder and family and domestic violence studies among African refugees [46-48]. A sample size of 359 (margin of error of 5\% with 95\% confidence) was estimated.

\section{Data Analysis}

Data were analysed using IBM Statistical Package for the Social Sciences (SPSS, Version 26). Descriptive statistics were generated for each of the demographic variables and presented as median, interquartile range (for skewed data) or mean and standard deviation (for normally distributed data) for continuous variables; and counts and percentages $(n, \%)$ for categorical variables. The associations between total Potentially Traumatic Events in country of birth and refugee country of participants were calculated and examined for each of the independent variables (Age Group, Country of Birth, Relationship 
Status, Highest Education, Profession and Length of Time in Australia). Prevalence of Repeat Potentially Traumatic Event was calculated as proportion (\%) of potentially traumatic events in refugee country and potentially traumatic events in country of birth.

\section{Results}

\section{Results}

\section{1) Sample characteristics.}

A total of 432 men completed the questionnaire. Hardcopy questionnaires were completed by 279 participants and online by 153 . Eleven questionnaires were not completed in entirety and thereby rendered invalid (total valid questionnaires: 421). As shown in Table 1, the minimum time spent in Australia by the participants was approximately one year and the maximum was 32 years with a median of 12 years. The median number of potentially traumatic events experienced by the participants was five (inter-quartile range: 2 to 8). Demographic descriptive statistics are displayed in Table 1 indicating Countries of Birth tabulated against: Age Group, Relationship Status, Highest Education and Profession.

Table 1: Sample characteristics.

\begin{tabular}{|c|c|c|c|c|c|c|c|c|c|c|c|}
\hline & $N=421$ & Eritrea & Ethiopia & Rwanda & $\begin{array}{l}\text { Congo } \\
\text { Braz }\end{array}$ & Sierra/Leo & $\begin{array}{l}\text { Congo } \\
\text { DRC }\end{array}$ & Liberia & Burundi & Somalia & Sudan/So \\
\hline & $\mathrm{n}$ & $\begin{array}{l}20 \\
(4.8 \%)\end{array}$ & $\begin{array}{l}66 \\
(15.7 \%)\end{array}$ & $\begin{array}{l}27 \\
(6.4 \%)\end{array}$ & $\begin{array}{l}25 \\
(5.9 \%)\end{array}$ & $40(9.5 \%)$ & $\begin{array}{l}55 \\
(13.1 \%)\end{array}$ & $\begin{array}{l}54 \\
(12.8 \%)\end{array}$ & $\begin{array}{l}30 \\
(7.1 \%)\end{array}$ & $\begin{array}{l}29 \\
(6.9 \%)\end{array}$ & $75(17.8 \%)$ \\
\hline \multicolumn{12}{|l|}{ Age Group } \\
\hline $18-24$ & 84 & 2 & 13 & 8 & 3 & 6 & 8 & 9 & 6 & 9 & 20 \\
\hline $25-34$ & 116 & 3 & 13 & 5 & 6 & 14 & 16 & 22 & 10 & 5 & 22 \\
\hline $35-44$ & 110 & 6 & 17 & 9 & 9 & 10 & 12 & 14 & 9 & 6 & 18 \\
\hline $45-54$ & 71 & 7 & 11 & 2 & 7 & 7 & 15 & 5 & 3 & 5 & 9 \\
\hline $55-64$ & 29 & 2 & 7 & 3 & 0 & 2 & 3 & 4 & 2 & 2 & 4 \\
\hline $65-70$ & 11 & 0 & 5 & 0 & 0 & 1 & 1 & 0 & 0 & 2 & 2 \\
\hline \multicolumn{12}{|l|}{ Relationship status } \\
\hline Never Married & 153 & 5 & 23 & 11 & 6 & 14 & 17 & 22 & 7 & 12 & 36 \\
\hline Married/De-facto & 223 & 14 & 39 & 14 & 12 & 19 & 32 & 26 & 20 & 15 & 32 \\
\hline Separated/Divorced/Widowed & 45 & 1 & 4 & 2 & 7 & 7 & 6 & 6 & 3 & 2 & 7 \\
\hline \multicolumn{12}{|l|}{ Highest Education } \\
\hline $\begin{array}{l}\text { Primary School and } \\
\text { Vocational Certificate }\end{array}$ & \multicolumn{10}{|c|}{ Vocational Certificate } & 18 \\
\hline Diploma & 104 & 5 & 17 & 6 & 6 & 9 & 16 & 15 & 10 & 4 & 16 \\
\hline Secondary School & 104 & 4 & 22 & 8 & 7 & 11 & 12 & 9 & 4 & 9 & 18 \\
\hline University Degree & 108 & 7 & 12 & 7 & 5 & 6 & 18 & 13 & 6 & 11 & 23 \\
\hline \multicolumn{12}{|l|}{ Profession } \\
\hline Health/Social Service & 90 & 6 & 16 & 4 & 7 & 8 & 11 & 12 & 8 & 9 & 9 \\
\hline Education & 24 & 2 & 3 & 2 & 2 & 2 & 2 & 3 & 2 & 0 & 6 \\
\hline Religion & 42 & 2 & 5 & 2 & 3 & 2 & 14 & 5 & 2 & 1 & 6 \\
\hline Student & 52 & 2 & 8 & 5 & 2 & 5 & 7 & 5 & 3 & 5 & 10 \\
\hline Engineering & 30 & 1 & 3 & 2 & 2 & 4 & 3 & 3 & 0 & 4 & 8 \\
\hline Casual Work & 55 & 1 & 5 & 3 & 5 & 6 & 4 & 11 & 3 & 4 & 13 \\
\hline Legal/Accountancy & 20 & 1 & 7 & 1 & 2 & 3 & 2 & 2 & 0 & 1 & 1 \\
\hline Other Professions & 108 & 5 & 19 & 8 & 2 & 10 & 12 & 13 & 12 & 5 & 22 \\
\hline
\end{tabular}


The prevalence of participants' exposure to potentially traumatic events in their country of birth their refugee country) and repeat potentially traumatic events [1] are presented in Table 2.

While experience of potentially traumatic events was common amongst the participants ( $81.0 \%$ had experienced at least one potentially traumatic event), the extent of traumatic exposure was associated with their country of birth. Although the participants left their country of birth to seek safety, this study shows that, overall, more than half of the participants who experienced potentially traumatic events in their country of birth also experienced at least one potentially traumatic event in their refugee country (denoted as Repeat Potentially Traumatic Event).

Country variations in the extent of potentially traumatic events were observed. For example as shown in Table 2, participants from Sudan/South Sudan had the highest Repeat Potentially Traumatic Event prevalence: $67.1 \%$ of the participants who were traumatised in their country of birth were also exposed to repeated potentially traumatic events in their refugee country. Participants from Congo (DRC) had the lowest Repeat Potential traumatic events (32.6\%).

Participants born in Congo (DRC) had the highest prevalence of potentially traumatic events in their country of birth with nearly all (95\%) exposed to at least one potentially traumatic event. The participants from Somalia, however, were least exposed to potentially traumatic events in their country of birth as $45 \%$ of the participants were exposed to at least one potentially traumatic event. In their refugee country, participants from Eritrea had the highest prevalence of potentially traumatic events as half of the participants were exposed to at least one. Participants from Somalia had the lowest potentially traumatic event exposure in their refugee country with $17 \%$ of the men exposed to at least one potentially traumatic event.

Table 2: Prevalence of Potential Traumatic Event (PTE) in Country of Birth (CB) Refugee Country (RC) and Repeat Potentially Traumatic Events by Country of Birth (CB).

\begin{tabular}{|c|c|c|c|c|c|c|}
\hline \multirow[t]{2}{*}{ Country of Birth } & & \multicolumn{2}{|c|}{ Country of Birth (CB) } & \multicolumn{2}{|c|}{ Refugee Country (RC) } & \multirow{3}{*}{$\begin{array}{l}\text { RPTE } \\
\text { Prevalence }^{1}\end{array}$} \\
\hline & & $\begin{array}{l}\text { PTE } \\
\text { Prevalence }^{3}\end{array}$ & $\begin{array}{l}\text { Measure of Central Tendency of } \\
\text { PTE }^{2}\end{array}$ & $\begin{array}{l}\text { PTE } \\
\text { Prevalence }\end{array}$ & $\begin{array}{l}\text { Measure of Central } \\
\text { Tendency }\end{array}$ & \\
\hline & $\mathrm{N}$ & n (\%) & Median (Q1-Q3) & PTE (\%) & Median (Q1-Q3) & \\
\hline Eritrea & 20 & $18(90)$ & $5.5(3.5-7.0)$ & $10(50)$ & $0.5(3.5-4.5)$ & 55.6 \\
\hline Ethiopia & 66 & $46(70)$ & $3.0(0.0-4.0)$ & $30(45)$ & $0.0(0.0-1.0)$ & 64.3 \\
\hline Rwanda & 27 & $23(85)$ & $6.0(2.0-7.0)$ & $13(48)$ & $0.0(0.0-5.0)$ & 56.5 \\
\hline $\begin{array}{l}\text { Congo } \\
\text { Brazzaville }\end{array}$ & 25 & $21(84)$ & $5.5(2.0-7.0)$ & $10(40)$ & $0.0(0.0-2.0)$ & 47.6 \\
\hline Sierra Leone & 40 & $34(85)$ & $4.5(1.5-7.0)$ & $18(45)$ & $0.0(0.0-3.0)$ & 52.9 \\
\hline Congo (DRC) & 55 & $52(95)$ & $4.0(3.0-7.0)$ & $17(31)$ & $0.0(0.0-1.0)$ & 32.6 \\
\hline Liberia & 54 & $50(93)$ & $6.0(2.0-8.0)$ & $25(46)$ & $0.0(0.0-3.0)$ & 49.5 \\
\hline Burundi & 30 & $26(87)$ & $5.5(2.0-7.0)$ & $14(47)$ & $0.0(0.0-3.0)$ & 54.0 \\
\hline Somalia & 29 & $13(45)$ & $0.0(0.0-2.0)$ & $5(17)$ & $0.0(0.0-0.0)$ & 37.8 \\
\hline $\begin{array}{l}\text { Sudan and } \\
\text { South Sudan }\end{array}$ & 75 & $57(76)$ & $3.0(1.0-6.0)$ & $38(51)$ & $1.0(0.0-4.0)$ & 67.1 \\
\hline Total $(\mathrm{N})$ & 421 & $340(81)$ & & $180(43)$ & & 53.1 \\
\hline
\end{tabular}

3) Prevalence of Potentially Traumatic Events by Age Group.

The prevalence of participants' exposure to potentially traumatic events in their country of birth, refugee country and repeat potentially traumatic events by Age Group is shown in Table 3. Participants aged between 45 and 54 years old had the highest potentially traumatic events prevalence in their country of birth as $89 \%$ were exposed to at least one potentially traumatic event. Participants aged between 18 and 24 years had the lowest prevalence as $63 \%$ were exposed to at least one potentially traumatic event in their country of birth. In the refugee country, participants aged between 65 and 70 years had the highest prevalence of potentially traumatic events as $73 \%$ were exposed to at least one potentially traumatic event. Participants aged 18 and 24 years had the lowest prevalence in the refugee country as $36 \%$ were exposed to at least one potentially traumatic event.

Participants aged between 65 and 70 years had the highest prevalence of repeat potentially traumatic events at $89 \%$. In contrast, participants aged between 55 and 64 years had the lowest prevalence of repeat potential traumatic events at $44.2 \%$.

Participants in the age groups $35-44,45-54,55-64$ and $65-70$ each had a median number of five potentially traumatic events as shown in table 3 . While participants in age group 25 - 34 had a median number of four potentially traumatic events, those aged between 18 and 24 had a median number of only one potentially traumatic event. These results show that older participants were exposed to more potentially traumatic events compared to the younger ones.

Table 3: Prevalence of Potential Traumatic Event (PTE)[3] in Country of Birth (CB) Refugee Country (RC) and Repeat Potentially Traumatic Events by Age Group 


\begin{tabular}{|c|c|c|c|c|c|c|}
\hline \multicolumn{2}{|c|}{ Age Group } & \multicolumn{2}{|c|}{ Country of Birth (CB) } & \multicolumn{2}{|c|}{ Refugee Country (RC) } & \multirow{3}{*}{ RPTE Prevalence [4] } \\
\hline & & $\begin{array}{l}\text { PTE } \\
\text { Prevalence }\end{array}$ & $\begin{array}{l}\text { Measure of Central Tendency of } \\
\text { PTE[5] }\end{array}$ & $\begin{array}{l}\text { PTE } \\
\text { Prevalence }\end{array}$ & $\begin{array}{l}\text { Measure of Central } \\
\text { Tendency }\end{array}$ & \\
\hline & $\mathrm{n}$ & $\mathrm{N}(\%)$ & Median (Q1-Q3) & $N(\%)$ & Median (Q1-Q3) & \\
\hline $18-24$ & 84 & $53(63)$ & $1.0(0.0-4.0)$ & $30(36)$ & $0.0(0.0-1.0)$ & 57.1 \\
\hline $25-34$ & 116 & $95(82)$ & $4.0(1.0-6.0)$ & $49(42)$ & $0.0(0.0-2.5)$ & 51.2 \\
\hline $35-44$ & 110 & $95(86)$ & $5.0(2.0-5.0)$ & $50(45)$ & $0.0(0.0-3.0)$ & 52.3 \\
\hline $45-54$ & 71 & $63(89)$ & $5.0(2.0-5.0)$ & $32(45)$ & $0.0(0.0-2.3)$ & 50.6 \\
\hline $55-64$ & 29 & $25(86)$ & $5.0(4.0-4.0)$ & $11(38)$ & $0.0(0.0-4.0)$ & 44.2 \\
\hline $65-70$ & 11 & $9(82)$ & $5.0(2.5-4.0)$ & $8(73)$ & $3.0(0.0-7.0)$ & 89.0 \\
\hline $\begin{array}{l}\text { Total } \\
\text { (N) }\end{array}$ & 421 & $340(81)$ & & $180(43)$ & & 53.1 \\
\hline
\end{tabular}

\section{4) Types of Potentially Traumatic Events Experienced in Country of Birth and Refugee Country}

The most reported potentially traumatic event experienced by participants in their country of birth was "War at Close Quarter" (experienced by 63.9\% of the participants) as shown in Table 4. Other reported potentially traumatic events experienced in their country of birth were Forced Separation (experienced by $57.3 \%$ of the participants); Family Member Loss (experienced by $55.9 \%$ of the participants) and Witnessing Physical Violence (experienced by $55.4 \%$ of the participants). The potentially traumatic event least reported by participants in their country of birth was Sexual Violence (experienced $22.5 \%$ of the participants). In their refugee country, the potentially traumatic event most commonly reported was Forced Separation (experienced by $28 \%$ of the participants). Other potentially traumatic events participants experienced in their refugee country were Family Member Loss (experienced by $25.4 \%$ of the participants); Witnessing Physical Violence (experienced by $24.9 \%$ of the participants) and Physical Violence (experienced by $21.1 \%$ of the participants). The least commonly reported potentially traumatic event in the refugee country was Sexual Violence (experienced by $9.2 \%$ of the participants).

Eritrean men had the highest prevalence of Physical Violence both in their country of birth (60\%) and refugee country (40\%). They also experienced the highest prevalence of Torture both in their country of birth (60\%) and refugee country (30\%). Rwandan men had the highest prevalence of Forced Separation both in the country of birth (77.8\%) and in refugee country (40.7\%). Rwandan men had the highest prevalence of War at Close Quarter in refugee country (33.3\%), Family Member Loss in refugee country (37\%) and Sexual Violence in the Country of birth (34.8\%). In their country of birth, men from Burundi experienced the highest prevalence of Family Member Loss (76.7\%) and Physical Violence (60\%). Eritrean and Sierra Leonean men had the same Physical Violence prevalence of $60 \%$ each in their country of birth.

Table 4: Types of Potentially Traumatic Events Experienced in Country of Birth and Refugee Country 


\begin{tabular}{|c|c|c|c|c|c|c|c|c|c|c|c|c|}
\hline \multirow{4}{*}{$\begin{array}{l}\text { Potential } \\
\text { traumatic } \\
\text { events }\end{array}$} & \multirow{3}{*}{ 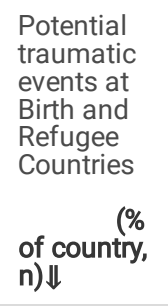 } & Eritrea & \multirow{2}{*}{$\begin{array}{l}\text { Ethiopia } \\
\mathrm{n}=66\end{array}$} & Rwanda & $\begin{array}{l}\text { Congo } \\
\text { Braz }\end{array}$ & Sierra/Leo & $\begin{array}{l}\text { Congo } \\
\text { (DRC) }\end{array}$ & Liberia & Burundi & Somalia & \multirow{2}{*}{$\begin{array}{l}\text { Sudan/South } \\
n=75\end{array}$} & \multirow{2}{*}{$\begin{array}{l}\text { TOTAL } \\
\mathbf{N}=421\end{array}$} \\
\hline & & $n=20$ & & $n=27$ & $n=25$ & $n=40$ & $\mathrm{n}=55$ & $n=54$ & $n=30$ & $n=29$ & & \\
\hline & & $(\%)$ & $(\%)$ & $(\%)$ & $(\%)$ & $(\%)$ & $(\%)$ & $(\%)$ & $(\%)$ & $(\%)$ & $(\%)$ & (\%) \\
\hline & $\begin{array}{l}\% \text { of } \\
\text { TOTAL N } \Rightarrow\end{array}$ & 4.8 & 15.7 & 6.4 & 5.9 & 9.5 & 13.1 & 12.8 & 7.1 & 6.9 & 17.8 & 100 \\
\hline \multirow{2}{*}{$\begin{array}{l}\text { War at } \\
\text { close } \\
\text { quarter }\end{array}$} & $\begin{array}{l}\text { Country of } \\
\text { Birth }\end{array}$ & 75.0 & 37.9 & 70.4 & 65.4 & 72.5 & 82.1 & 81.8 & 73.3 & 27.6 & 60.0 & 63.9 \\
\hline & $\begin{array}{l}\text { Refugee } \\
\text { Country }\end{array}$ & 20.0 & 16.7 & 33.3 & 12.0 & 15.0 & 12.7 & 25.9 & 10.0 & 13.8 & 22.7 & 18.5 \\
\hline \multirow[t]{2}{*}{$\begin{array}{l}\text { Forced } \\
\text { Separation }\end{array}$} & $\begin{array}{l}\text { Country of } \\
\text { Birth }\end{array}$ & 70.0 & 45.5 & 77.8 & 65.4 & 55.0 & 69.6 & 70.9 & 63.3 & 20.7 & 48.0 & 57.3 \\
\hline & $\begin{array}{l}\text { Refugee } \\
\text { Country }\end{array}$ & 40.0 & 30.3 & 40.7 & 28.0 & 25.0 & 21.8 & 29.6 & 23.3 & 17.2 & 29.3 & 28.0 \\
\hline \multirow{2}{*}{$\begin{array}{l}\text { Family } \\
\text { member } \\
\text { Loss }\end{array}$} & $\begin{array}{l}\text { Country of } \\
\text { Birth }\end{array}$ & 70.0 & 42.4 & 66.7 & 69.2 & 57.5 & 64.3 & 63.6 & 76.7 & 13.8 & 50.7 & 55.9 \\
\hline & $\begin{array}{l}\text { Refugee } \\
\text { Country }\end{array}$ & 30.0 & 19.7 & 37.0 & 36.0 & 27.5 & 21.8 & 24.1 & 33.3 & 6.9 & 28.0 & 25.4 \\
\hline \multirow{2}{*}{$\begin{array}{l}\text { Physical } \\
\text { violence or } \\
\text { assault }\end{array}$} & $\begin{array}{l}\text { Country of } \\
\text { Birth }\end{array}$ & 60.0 & 22.7 & 59.3 & 50.0 & 60.0 & 53.6 & 58.2 & 60.0 & 6.9 & 44.0 & 46.0 \\
\hline & $\begin{array}{l}\text { Refugee } \\
\text { Country }\end{array}$ & 40.0 & 12.1 & 18.5 & 20.0 & 25.0 & 16.4 & 24.1 & 16.7 & 6.9 & 32.0 & 21.1 \\
\hline \multirow{2}{*}{$\begin{array}{l}\text { Witnessing } \\
\text { physical } \\
\text { violence }\end{array}$} & $\begin{array}{l}\text { Country of } \\
\text { Birth }\end{array}$ & 75.0 & 36.4 & 70.4 & 69.2 & 65.0 & 55.4 & 69.1 & 70.0 & 27.6 & 46.7 & 55.4 \\
\hline & $\begin{array}{l}\text { Refugee } \\
\text { Country }\end{array}$ & 35.0 & 15.2 & 33.3 & 24.0 & 30.0 & 18.2 & 27.8 & 20.0 & 10.3 & 36.0 & 24.9 \\
\hline \multirow[t]{2}{*}{ Torture } & $\begin{array}{l}\text { Country of } \\
\text { Birth }\end{array}$ & 60.0 & 24.2 & 44.4 & 38.5 & 37.5 & 46.4 & 49.1 & 43.3 & 6.9 & 34.7 & 37.5 \\
\hline & $\begin{array}{l}\text { Refugee } \\
\text { Country }\end{array}$ & 30.0 & 15.2 & 22.2 & 12.0 & 7.5 & 12.7 & 20.4 & 6.7 & 3.4 & 22.7 & 15.7 \\
\hline \multirow[t]{2}{*}{$\begin{array}{l}\text { Sexual } \\
\text { Violence }\end{array}$} & $\begin{array}{l}\text { Country of } \\
\text { Birth }\end{array}$ & 27.8 & 8.2 & 34.8 & 34.8 & 18.9 & 27.8 & 30.8 & 34.5 & 7.7 & 17.8 & 22.5 \\
\hline & $\begin{array}{l}\text { Refugee } \\
\text { Country }\end{array}$ & 0.0 & 6.6 & 17.4 & 9.1 & 5.4 & 3.8 & 13.7 & 13.8 & 0.0 & 15.1 & 9.2 \\
\hline \multirow{2}{*}{$\begin{array}{l}\text { Other } \\
\text { frightening } \\
\text { situation(s) }\end{array}$} & $\begin{array}{l}\text { Country of } \\
\text { Birth }\end{array}$ & 55.0 & 43.9 & 48.1 & 53.8 & 62.5 & 44.6 & 72.7 & 46.7 & 24.1 & 38.7 & 48.8 \\
\hline & $\begin{array}{l}\text { Refugee } \\
\text { Country }\end{array}$ & 35.0 & 18.2 & 18.5 & 8.0 & 22.5 & 12.7 & 14.8 & 10.0 & 6.9 & 16.0 & 15.9 \\
\hline \multirow{2}{*}{$\begin{array}{l}\text { At least one } \\
\text { Potential } \\
\text { traumatic } \\
\text { event }\end{array}$} & $\begin{array}{l}\text { Country of } \\
\text { Birth/ }\end{array}$ & 90.0 & 70.0 & 85.0 & 84.0 & 85.0 & 95.0 & 93.0 & 87.0 & 45.0 & 76.0 & 81.0 \\
\hline & $\begin{array}{l}\text { Refugee } \\
\text { Country }\end{array}$ & & & & & & & & & & & \\
\hline
\end{tabular}

[1] The Office of Multicultural Interests (OMI) is a division of the Department of Local Government, Sport and Cultural Industries of government of Western Australia. OMI develops strategies that include everyone-culturally diverse communities, the wider community, business and industry groups, government, and non-government agencies-to help develop a society that values and maximises the benefits of its cultural diversity.

[1]. RPTE Prevalence $=$ Proportion $(\%)$ of PTE Prevalence at RC and PTE Prevalence at CB

[2]. Minimum Potential Traumatic Event $(\mathrm{PTE})=0$, Maximum Potential Traumatic Event $(\mathrm{PTE})=8$

[3]. PTE Prevalence $=$ Percentage of participants with a Potential Traumatic Event 
[3] Prevalence of Potentially Traumatic Event = Percentage of participants with a Potentially Traumatic Event

[4] RPTE Prevalence= Proportion (\%) of PTE Prevalence at RC and PTE Prevalence at CB

[5] Minimum Potential Traumatic Event $(\mathrm{PTE})=0$, Maximum Potential Traumatic Event $(\mathrm{PTE})=8$

\section{Discussion}

This is the first study to our knowledge to identify the prevalence of potentially traumatic events experienced by African men from a refugee background in Australia. Congruent with studies of East African Refugees in the United States [49] and Sierra Leonean refugees in Gambia [50], the prevalence of potentially traumatic experiences was high, with more than $81 \%$ of the participants exposed to at least one potentially traumatic event. A unique aspect of this investigation's findings is that participants were not only exposed to potentially traumatic events in their country of birth, but also that $43 \%$ of them were further exposed in their refugee country.

The findings are important for public health and to aid understanding the experiences of African refugees in WA. Three crucial findings from this study with public health implications include the high prevalence of potentially traumatic experiences, high prevalence of repeated potentially traumatic experiences in refugee countries and, the heterogeneous prevalence of potentially traumatic events across countries and different age groups.

Our findings noted a high prevalence of potentially traumatic events with 340 (81\%) men from war-torn African countries now living in WA being exposed to at least one potentially traumatic event prior to their settlement in Australia. This result is consistent with a study by Fox and Tang (2000) examining Sierra Leonean refugee experiences which found that more than $90 \%$ of participants experienced potentially traumatic events [50]. A study on pre-migration trauma experiences of East African refugees in the US found that potentially traumatic events were experienced by at least 75\% of male and female participants [51]. Furthermore, a state-wide survey conducted in WA using a structured questionnaire showed that potentially traumatic events are among the factors that contribute to a person being mentally unhealthy or vulnerable to mental health problems [52]. Similarly, a study of the mental health of African, South-Eastern Asian, and Western/Southern Asian refugee adults in WA shows that potentially traumatic events are associated with probable PTSD, and high Kessler Psychological Distress Scale (K10) mean scores [53].

Our study demonstrates that more than half of African male refugees in WA who have experienced potentially traumatic events in their country of birth also experience one or more additional potentially traumatic events in their refugee countries. This high prevalence of potentially traumatic exposure, both in their country of birth and, more disturbingly, repeated exposure in their refugee country has some serious public health implications. For instance, repeated potentially traumatic events experienced by the participants have been associated with difficulties of settling in Australia resulting in many African refugees taking time to develop trust with Australians and Australian government agencies as shown in previous study on Sudanese refugees in Australia [54]. Repeated potentially traumatic experiences are also associated with feelings of insecurity, self-blame, disappointment and disenfranchisement [55]. Furthermore, health professionals "who work with survivors of more extreme or prolonged and repeated traumatisation (e.g., sustained childhood sexual abuse, confinement in a concentration camp, extended domestic violence, war, torture) have noted that the symptom patterns observed are more complex than those encompassed by the PTSD category" [56 p.19]. Therefore, it can be suggested that identifying and responding to the cumulative impact of potentially traumatic events experienced in both their country of birth and refugee country could reduce the risk of behavioural, mental health and other psychiatric issues in future.

The prevalence of potentially traumatic events in participants' country of birth ranged from $45.0 \%$ (Somalia) to $95.0 \%$ (Congo (DRC)) demonstrating the magnitude and intensity of the potentially traumatic events the participants were exposed to varied between the countries of origin. The implications for public health of the impact of these potentially traumatic events indicate that there may be a lack of homogeneity and, rather, experiences vary depending on the country of descent. The impact of these events may also manifest differently. This, therefore, suggests that any one intervention may not be effective for all refugees from all African countries.

There is evidence that heterogeneous traumatic exposures are associated with high comorbid disorders suggesting that impact of traumatic exposures affecting population subgroups could manifest underlying unobserved characteristics [57]. The distribution of potentially traumatic events shows three severity groupings: severe potentially traumatic events with median number greater than five (Liberia, Rwanda, Congo Brazzaville, Burundi and Eritrea), moderate number of potentially traumatic events with median number of three to five (Ethiopia, Sierra Leone, Congo DRC and Sudan/South Sudan) and low number of potentially traumatic events with median number less than three (Somalia).

There was also variation in prevalence of potentially traumatic events experienced in country of birth among the Age Groups ranging from 63\% (18-24 years) to $89 \%$ (45-54 years). The lower prevalence among men aged between 18 and 24 years is likely due to many being too young or not yet born to be exposed to the wars that ended between 1990 and 2009. Conversely, it is likely that men currently aged between 45 and 54 years had the highest prevalence of potentially traumatic events because they would have been adults during the war years and hence, had a higher likelihood of exposure to war and potentially traumatic events.

Some specific potentially traumatic events such as Torture, Physical Violence and Sexual Violence experienced by refugee men in the study have important implications. In their country of birth, approximately $50 \%$ of participants experienced Torture, over $50 \%$ experienced Physical Violence and approximately $23 \%$ experienced Sexual Violence. Survivors of torture and other organised violence are usually overwhelmed by feelings of guilt, shame, mistrust; and commonly complain of symptoms, such as sleeplessness, nightmares, weakness, lethargy, headaches and abdominal pain [58]. In addition, a study by Stepakoff et al indicated that Liberian and Sierra Leonean refugees in Guinea who experienced war torture were left with deep psychological scars such as depression, lethargy, hopelessness, anxiety, and posttraumatic stress and were unable to make meaningful contributions to their families and communities [18]. 
Our study established that about one half of the participants experienced physical violence in their country of birth and $21.1 \%$ in their refugee countries. The public health implications of physical violence may include effects on the brain, neuroendocrine system, and immune response which may result in increased incidences of depression, anxiety, posttraumatic stress disorder, and suicide; increased risk of cardiovascular disease; and premature mortality [59]. Research suggests that Sudanese refugees in Australia who experienced physical violence such as beating, gunshot wounds, and brutal interrogations reported feelings of insecure and perpetual fear both of the violence itself and of the possibility that it would lead to their death as they continually thought about death and never felt safe [54].

Our findings on the prevalence of sexual violence show that approximately $35 \%$ of men experienced sexual violence in Rwanda, Congo Brazzaville, and Burundi. This finding aligns with a previous review that indicated that $32.6 \%$ of Liberian former male combatants and $7.4 \%$ of non-combatant males experienced sexual violence [60]. Previous studies have suggested that sexual violence inflicts negative social and psychological consequences on the survivors, their families and communities [60]. Sexual violence against men poses serious public health consequences which need to be taken into consideration when designing any impactful intervention for men. For instance research on sexual violence against men and boys suggested that it has both physical (sexually transmitted infections, incontinence, genital and rectal impairment, infertility, sexual dysfunction) and mental health (depression, anxiety, PTSD, suicidal ideation) impact on the victims [61].

For agencies involved in developing and delivering counselling and other interventions to African men from a refugee background, the results of the current study highlight the importance of considering incorporating therapeutic treatments for potentially traumatic exposures in their interventions. The findings also highlight the need for deliberate policies to address the impact of potentially traumatic exposures experienced by African refugee men. Current short-term torture and trauma counselling in Australia provided for new arrivals under the Humanitarian Settlement Strategy (HSS) programme does not specifically address their potentially traumatic exposures. To facilitate the settlement of African refugees in Australia, this program should be modified to provide sufficient counselling sessions addressing the intensity of war-related repeated potentially traumatic events they experienced.

\section{Strengths And Limitations}

This study has several strengths. The robust sample size exceeded the sample size necessary to estimate the prevalence of potentially traumatic events of men of African descent in WA. This assists with neutralising erroneous responses from the participants [62]. The data used in the study were collected using a validated instrument. Analysis of the response rate and demographic profile of participants from each country indicates that the results are reasonably representative of the populations studied.

The study also has some limitations. As non-probability sampling was used, the opportunity to participate was not equal for all qualified participants in the target population, and the study results are thus not necessarily generalisable to all African refugee men in WA [63]. The researchers acknowledge the potential for selection bias. It is possible that participants in the research are from only those who attended the community events, those who accessed community organisations online and those who received information from OMI. Furthermore, as this study is a cross-sectional study, the findings do not establish causality. Whilst the questionnaire was also available in Swahili, literacy issues may have prevented or discouraged some men from participating in the research.

\section{Conclusion}

A remarkable deduction to be drawn from this paper is that potentially traumatic event exposures are far from rare amongst men of African refugee background. This study shows the heterogeneity of these potentially traumatic experiences and highlights the importance of designing and implementing appropriate trauma-informed interventions and treatments for African men exposed to potentially war traumatic events. The study also underscores the need to prioritise interventions for those from countries with high potentially traumatic events exposures. Further studies are needed to explore the impact of potentially traumatic events on refugee populations, particularly in terms of their mental health.

\section{Declarations}

- Ethics approval and consent to participate: The approval for this study was obtained from Human Ethics of The University of Western Australia (file reference - RA/4/20/5653). All the respondents gave consent to participate in the survey.

- Consent for publication: Not applicable

- Availability of data and material: All data generated or analysed during this study are included in this published article

- Competing interests: The authors declare that they have no competing interests

- Funding: This study was part of a PhD thesis and was supported by The University of Western Australia.

- Authors' contributions: EON conducted data collection, analysis and interpretation of the results, and drafted the manuscript. CF assisted in data collection, guided data analysis and interpretation and critically revised the document before submission. LS and KM guided data analysis and interpretation and critically revised the document before submission

- Acknowledgements: We want to acknowledge the assistance of OMI in advertising the study; African community leaders in WA for supporting the project; the respondents for participating in the project; and Dr Charley Budgeon, Dr Victor Oguoma and Gbenga Afolayan for their support and assistance.

\section{- Authors' information}

1. Ernest O Nnadigwe: School of Population and Global Health, The University of Western Australia. E: ernest.nnadigwe@research.uwa.edu.edu.au 
2. Prof Colleen Fisher: School of Population and Global Health, The University of Western Australia.

E: colleen.fisher@uwa.edu.au

3. Lisa Wood: School of Population and Global Health, The University of Western Australia.

E: lisa.wood@uwa.edu.au

4. Karen Martin: School of Population and Global Health, The University of Western Australia. 4

E: martin@uwa.edu.au

\section{References}

1. Pedersen D. Political violence, ethnic conflict, and contemporary wars: broad implications for health and social well-being. Soc Sci Med. 2002;55(2):17590.

2. Neuner F, et al. Psychological trauma and evidence for enhanced vulnerability for posttraumatic stress disorder through previous trauma among West Nile refugees. BMC Psychiatry. 2004;4(1):1-7.

3. Diagnostic and statistical manual of mental disorders: DSM-5. Fifth edition. ed. American Psychiatric Association. Diagnostic and statistical manual of mental disorders, Fifth edition. 2013, Arlington, VA: American Psychiatric Association.

4. Hein J. Refugees, immigrants, and the state. Ann Rev Sociol. 1993;19(1):43-59.

5. Flahaux M-L, De Haas H. African migration: trends, patterns, drivers. Comparative Migration Studies. 2016;4(1):1-25.

6. Balint R, Simic Z. Histories of migrants and refugees in Australia. Australian Historical Studies. 2018;49(3):378-409.

7. Jakubowicz A, Australia's migration policies: African dimensions. Online. (http://www. humanrights. gov. au/africanaus/papers/africanaus_paper_jakubowicz. doc), 2010.

8. Hugo G. Migration between Africa and Australia: a demographic perspective. Australian Human Rights Commission: Sydney; 2009.

9. Ammons L. Consequences of war on African countries' social and economic development. Afr Stud Rev. 1996;39(1):67-82.

10. Fisher C. Changed and changing gender and family roles and domestic violence in African refugee background communities post-settlement in Perth, Australia. Violence Against Women. 2013;19(7):833-47.

11. Musisi S. Mass trauma and mental health in Africa. African Health Sciences. 2004;4(2):80-2.

12. Ehntholt KA, Yule W. Practitioner Review: Assessment and treatment of refugee children and adolescents who have experienced war-related trauma. J Child Psychol Psychiatry. 2006;47(12):1197-210.

13. Ba I, Bhopal R. Physical, mental and social consequences in civilians who have experienced war-related sexual violence: a systematic review (19812014). Public Health. 2017;142:121-35.

14. Chol C, et al. Health system reforms in five sub-Saharan African countries that experienced major armed conflicts (wars) during 1990-2015: a literature review. Global health action. 2018;11(1):1517931.

15. Karam EG, et al. Major depression and external stressors: the Lebanon Wars. Eur Arch Psychiatry Clin Neurosci. 1998;248(5):225-30.

16. Karam EG, et al. Lifetime prevalence of mental disorders in Lebanon: first onset, treatment, and exposure to war. PLoS Med. $2008 ; 5(4): e 61$.

17. Betancourt TS, et al. Trauma history and psychopathology in war-affected refugee children referred for trauma-related mental health services in the United States. J Trauma Stress. 2012;25(6):682-90.

18. Stepakoff S, et al. Trauma healing in refugee camps in guinea: A psychosocial program for Liberian and Sierra Leonean survivors of torture and war. Am Psychol. 2006;61(8):921.

19. Pokhariyal GP, Rono R, Munywoki S. Analysis of treatment methods for victims of torture in Kenya and East Africa region. Traumatology. 2013;19(2):10717.

20. Schaal S, et al. Posttraumatic stress disorder according to DSM-5 and DSM-IV diagnostic criteria: a comparison in a sample of Congolese ex-combatants. European Journal of Psychotraumatology. 2015;6(1):24981.

21. Chan M. Mental health and development: targeting people with mental health conditions as a vulnerable group. World Health Organization. 2010;3(1):111-21.

22. Herman JL. Complex PTSD: A syndrome in survivors of prolonged and repeated trauma. Journal of traumatic stress. 1992;5(3):377-91.

23. Palic S, et al. Evidence of complex posttraumatic stress disorder (CPTSD) across populations with prolonged trauma of varying interpersonal intensity and ages of exposure. Psychiatry Res. 2016;246:692-9.

24. Collins S, Long A. Working with the psychological effects of trauma: consequences for mental health-care workers-a literature review. J Psychiatr Ment Health Nurs. 2003;10(4):417-24.

25. Puteho PC. Critical Assessment of the Australian Settlement Process: Case Study of the African Humanitarian Entrants in Australia. University of Canberra; 2015.

26. Fozdar F, Hartley L. Refugee resettlement in Australia: What we know and need to know. Refugee Survey Quarterly. 2013;32(3):23-51.

27. Zelechoski AD, et al. Traumatized youth in residential treatment settings: Prevalence, clinical presentation, treatment, and policy implications. Journal of Family Violence. 2013;28(7):639-52.

28. Herrmann S, et al. The impact of visa status and Medicare eligibility on people diagnosed with HIV in Western Australia: a qualitative report. Sexual Health. 2012;9(5):407-13. 
29. Clark JF, Resource Revenues and Political Development in Sub-Saharan Africa Congo Republic in Comparative Perspective. Africa Spectrum, 2002: p. 2541.

30. Bernal V. Eritrea goes global: Reflections on nationalism in a transnational era. Cult Anthropol. 2004;19(1):3-25.

31. Jones BD. Peacemaking in Rwanda: the dynamics of failure. Refugee Survey Quarterly, 2002. 21(3).

32. Binningsbø HM, Dupuy K. Using power-sharing to win a war: The implementation of the Lomé Agreement in Sierra Leone. Afr Spectr. 2009;44(3):87-107.

33. Eriksson M, Wallensteen P. Armed Conflict, 1989-2003. Journal of Peace Research. 2004;41(5):625-36.

34. Bruthus L. Zero tolerance for Liberian rapists. Forced Migration Review. 2007;27:35.

35. Hopkins DR, et al. Dracunculiasis eradication: the final inch. Am J Trop Med Hyg. 2005;73(4):669-75.

36. Reyntjens F. Briefing: Burundi: a peaceful transition after a decade of war? African Affairs. 2006;105(418):117-35.

37. Harbom L, Wallensteen P. Armed Conflicts, 1946-2009. Journal of Peace research. 2010;47(4):501-9.

38. Guha M. Diagnostic and statistical manual of mental disorders: DSM-5. Reference Reviews; 2014.

39. Sar V, Ozturk E. What is trauma and dissociation? Journal of Trauma Practice. 2006;4(1-2):7-20.

40. Panter AT, Sterba SK. Handbook of ethics in quantitative methodology. 2011: Taylor \& Francis.

41. Flynn M, Wickramage K. Leveraging the domain of work to improve migrant health. Int J Environ Res Public Health. 2017;14(10):1248.

42. Liu Y, Xia JC, Phatak A, Evaluating the Accuracy of Bluetooth-Based Travel Time on Arterial Roads: A Case Study of Perth, Western Australia. Journal of Advanced Transportation, 2020. 2020.

43. Australian Bureau of Statistics. Country of birth Statistics. Australian Bureau of Statistics; 2016.

44. Kim J, et al. A Review of Health Survey Research for People with Refugee Background Resettled from Africa: Research Gaps and Methodological Issues. Journal of racial ethnic health disparities. 2019;6(1):160-81.

45. Guillera-Arroita G, Lahoz-Monfort JJ. Designing studies to detect differences in species occupancy: power analysis under imperfect detection. Methods Ecol Evol. 2012;3(5):860-9.

46. World Health Organization. Global and regional estimates of violence against women: prevalence and health effects of intimate partner violence and nonpartner sexual violence. World Health Organization; 2013.

47. Onyut LP, et al. Trauma, poverty and mental health among Somali and Rwandese refugees living in an African refugee settlement-an epidemiological study. Conflict health. 2009;3(1):6.

48. Karunakara UK, et al. Traumatic events and symptoms of post-traumatic stress disorder amongst Sudanese nationals, refugees and Ugandans in the West Nile. Afr Health Sci. 2004;4(2):83-93.

49. Shook B, et al. Pre-Migration Trauma Experiences of East African Refugees in the United States. Am Int J Contemp Res. 2018;8(1):12-23.

50. Fox SH, Tang SS. The Sierra Leonean refugee experience: Traumatic events and psychiatric sequelae. J Nerv Ment Dis. 2000;188(8):490-5.

51. Shook B, et al. Pre-Migration Trauma Experiences of East African Refugees in the United States. American International Journal of Contemporary Research. 2018;8(1):12-23.

52. Donovan RJ, et al. People's beliefs about factors contributing to mental health: implications for mental health promotion. Health Promotion Journal of Australia. 2007;18(1):50-6.

53. Lillee A, Thambiran A, Laugharne J. Evaluating the mental health of recently arrived refugee adults in Western Australia. Journal of Public Mental Health, 2015.

54. Khawaja NG, et al. Difficulties and coping strategies of Sudanese refugees: A qualitative approach. Transcult Psychiatry. 2008;45(3):489-512.

55. Browne C, Winkelman C. The effect of childhood trauma on later psychological adjustment. Journal of Interpersonal Violence. 2007;22(6):684-97.

56. Ehrenreich JH. Understanding PTSD: forgetting "trauma". Analyses of Social Issues Public Policy. 2003;3(1):15-28.

57. Nugent NR, Koenen KC, Bradley B. Heterogeneity of posttraumatic stress symptoms in a highly traumatized low income, urban, African American sample. J Psychiatr Res. 2012;46(12):1576-83.

58. Burnett A, Peel M. The health of survivors of torture and organised violence. Bmj. 2001;322(7286):606-9.

59. Rivara F, et al. The effects of violence on health. Health Aff. 2019;38(10):1622-9.

60. Solangon S, Patel P. Sexual violence against men in countries affected by armed conflict. Conflict, Security Development, $2012.12(4)$ : 417-42.

61. Chynoweth SK, Freccero J, Touquet H. Sexual violence against men and boys in conflict and forced displacement: implications for the health sector. Reprod Health Matters. 2017;25(51):90-4.

62. Potocky-Tripodi M. The role of social capital in immigrant and refugee economic adaptation. Journal of Social Service Research. 2004;31(1):59-91.

63. Etikan I, Musa SA, Alkassim RS. Comparison of convenience sampling and purposive sampling. American journal of theoretical applied statistics. 2016;5(1):1-4. 